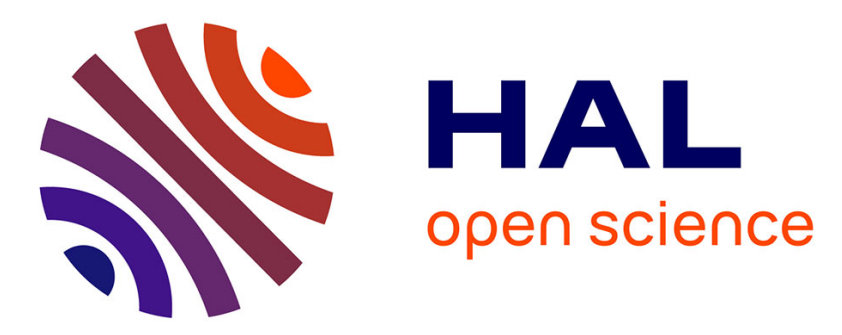

\title{
A linear programming approach to optimize demand response for water systems under water demand uncertainties
}

Chouaib Mkireb, Abel Dembele, Antoine Jouglet, Thierry Denoeux

\section{To cite this version:}

Chouaib Mkireb, Abel Dembele, Antoine Jouglet, Thierry Denoeux. A linear programming approach to optimize demand response for water systems under water demand uncertainties. 7th IEEE International Conference on Smart Grid and Clean Energy Technologies (ICSGCE 2018), 2018, Kajang, Malaysia. pp.206-211, 10.1109/ICSGCE.2018.8556696 . hal-02006661

\section{HAL Id: hal-02006661 \\ https://hal.science/hal-02006661}

Submitted on 5 Jul 2021

HAL is a multi-disciplinary open access archive for the deposit and dissemination of scientific research documents, whether they are published or not. The documents may come from teaching and research institutions in France or abroad, or from public or private research centers.
L'archive ouverte pluridisciplinaire HAL, est destinée au dépôt et à la diffusion de documents scientifiques de niveau recherche, publiés ou non, émanant des établissements d'enseignement et de recherche français ou étrangers, des laboratoires publics ou privés. 


\section{A linear programming approach to optimize demand response for water systems under water demand uncertainties.}

\author{
Chouaïb Mkireb and Abel Dembele \\ Suez Smart Solutions \\ 38 Avenue du président Wilson, 78320 \\ Le Pecq, France \\ c.mkireb@suez.com; abel.dembele@suez.com
}

\author{
Antoine Jouglet and Thierry Denoeux \\ Sorbonne universités, Université de Technologie de \\ Compiègne, CNRS, Heudiasyc, UMR 7253 \\ CS 60319, 60230 Compiègne, France \\ antoine.jouglet@hds.utc.fr; thierry.denoeux@utc.fr
}

\begin{abstract}
Worldwide efforts to accelerate energy transition require consumers acting like prosumers in energy markets. Demand side management is believed to facilitate the integration of high share of renewables into the electric power grid, and contributes to the reduction of $\mathrm{CO}_{2}$ emissions by reducing peak power load. Drinking Water Systems, by the presence of storage units and variable speed pumps, can address energy efficiency mechanisms such as Demand Response. In this paper, we use linear programming to optimize pump schedules in Drinking Water Systems while trading Demand Response in a spot power market during peak times. Uncertainties about water demands are taken into account in the mathematical model allowing to propose power reductions in the day-ahead spot power market, covering potential risks of real-time water demand forecasting inaccuracy.
\end{abstract}

Keywords-Drinking Water Systems, Demand Response, spot power market, peak energy load

\section{INTRODUCTION}

The objectives of energy transition involve major changes in the operating mode of transmission and distribution electric power networks. On the supply side, the world is experiencing a massive integration of renewable decentralized generation. On the demand side, the world is experiencing a rapid increase in electricity consumption [1], mainly due to the development of new usages of electricity: electric vehicles, heat pumps, etc... Due to the low storage capacity of electricity, these changes make the exercise of balancing the electric power system very arduous, and imply a growing need to develop efficient methods for demand side management [2]. Demand management, also known as Demand Response (DR), is the change in the power consumption of an electric utility consumer in response to a given signal. It requires active consumers in energy markets, known as "prosumers", adapting their electricity demand to the available generation and price signals in wholesale markets. Industrial processes with storage units (warehouse, electric batteries) are believed to be the best candidates for DR since they have an electric flexibility they can use to optimize their productivity while helping to manage several situations for power network management [3]. The benefits from this participation include:

- Reducing the risk of service interruptions caused by supply shortage, transmissions congestions or rolling blackouts;

- Reducing the use of fossil generation units to deal with peak demands and then reducing $\mathrm{CO} 2$ emissions;

In this paper, the case of a highly energy intensive industry is discussed, which is the Drinking Water industry. First, water system's flexibility and their potential to reduce peak load is discussed. After, the French model allowing to trade DR directly to spot markets is presented. In section III is presented the mathematical model allowing water systems to optimize their participation in the spot market while anticipating uncertainties on water demands. Finally, some numerical results, interpretations and future directions are discussed in the last section.

\section{Drinking Water Systems Acting LiKe Prosumers}

This section presents the potential for electrical flexibility of drinking water systems. Then, the particular DR mechanism considered for our study is discussed.

\section{A. Drinking Water System's Flexibility}

Drinking water systems can account for up to $5 \%$ of a city's total electricity consumption [4] and more than two thirds is used by electric pumps [5]. In fact, pumps are highly energy-intensive since they operate continuously to ensure a sufficient level of water autonomy to tanks and reservoirs in anticipation of uncertainties on water consumption. At the same time, drinking water systems have a considerable electrical flexibility thanks to the presence of storage units (reservoirs, tanks) and variable speed pumps. Indeed, this flexibility is generally used to optimize energy costs by optimizing the pump schedules according to different electricity time of use tariffs.

Past years have realised several advances in smart grid technologies and progressive change in electricity market 
rules by regulatory agencies [6]. These changes have contributed to the implementation of smart technologies like advanced metering infrastructures and the removal of barriers for DR participation in electricity markets. At the same time, the water industry benefited from the development of both sophisticated Supervisory Control and Data Acquisition (SCADA) systems and Programmable Logic Controller (PLC), allowing water utilities to control and optimize the water production process, from its capture to final distribution. Thanks to these progress, drinking water systems could use their flexibility (storage units + variable-speed pumps) in order to improve power system's reliability through DR [7]. They could act like active prosumers and interact in real time with energy markets and Transmission System Operators (TSO), and participate in efficient DR programs, by adapting their electricty consumption to the needs of the electric power system.

\section{B. Demand Response in the French Spot Power Market}

In France, DR operators are in competition with energy suppliers to value the flexibility of consumers. They can therefore trade DR on electricity markets without prior agreement of suppliers [8]. This opportunity offered to encourage DR operators had been accompanied by important regulatory work to define the rules and modalities for the exchange of financial and energy flows between different market players.

In 2014, France set up a mechanism, called "NEBEF" mechanism, allowing to trade DR directly in spot (D-1) power markets as a resource [9]. In this context, the DR operator sells in day $\mathrm{D}$ at midday, the electricity which will not be consumed in day $\mathrm{D}+1$ by the consumer, and compensate financially the supplier of the site participating in the NEBEF mechanism (see Fig. 1). In other terms, the DR operator buys the energy from the supplier at a regulated price, called compensation, to compensate him for the energy he has injected into the network. The supplier continues then its injections as planned and the DR operator sells in the spot market the energy that the consumer would not have to consume.

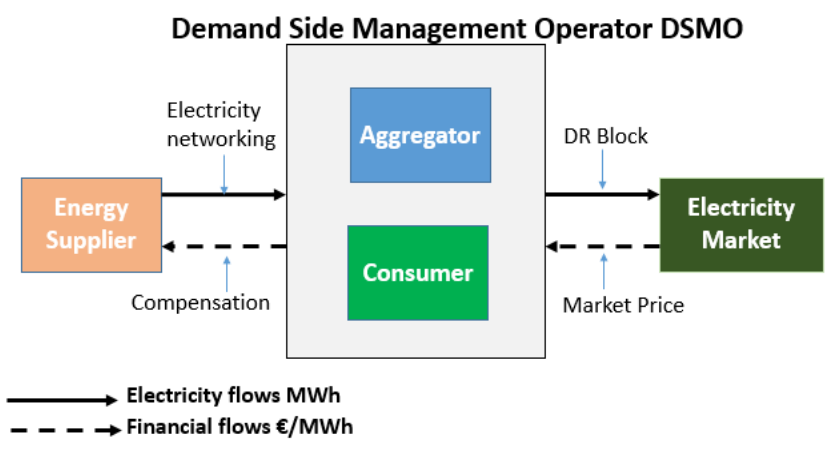

Fig. 1. NEBEF mechanism.

France has implemented this mechanism to reduce peak power load, especially during cold winters. These periods experience growth of $2300 \mathrm{MW}$ of load between 18:00 and 20:00 for each degree Celsius less of temperature, in what we call a thermo-sensibility phenomenon [10]. The mechanism contributes to the reduction of the use of fossil power plants, and then $\mathrm{CO} 2$ emissions, to deal with these peak load periods.
In the absence of dynamic energy pricing in French retail markets, this mechanism is also a way to expose endconsumers to dynamic electricity prices encouraging them to modulate their consumption according to wholesale market price signals.

For the NEBEF mechanism, each DR bid on the spot market must constitute at least $100 \mathrm{~kW}$ of power reduction. In addition, DR bids cannot exceed a maximum of two hours per block [9]. The method of estimating the real load curtailed by the DR operator during a DR event consists in comparing two curves:

- Reference curve: the minimum between the mean electric loads just before (past reference) and just after (post reference) the DR event, over a period of time equal to that of the DR event.

- DR curve: mean electric load during the DR event.

The load curtailed during a DR event is equal to the difference between the reference curve and the DR curve (see Fig. 2). This estimation method is called the corrected double reference method and is used by the French Transmission System Operator RTE (Réseau Transport d'Electricité) in order to quantify the real power reduction achieved by the consumer.

Compensation prices are regulated and fixed at the end of each year by RTE on the basis of observed spot prices during the year [9]. They depend on the season, type of the day (working/non-working), and time (peak/off-peak hours).

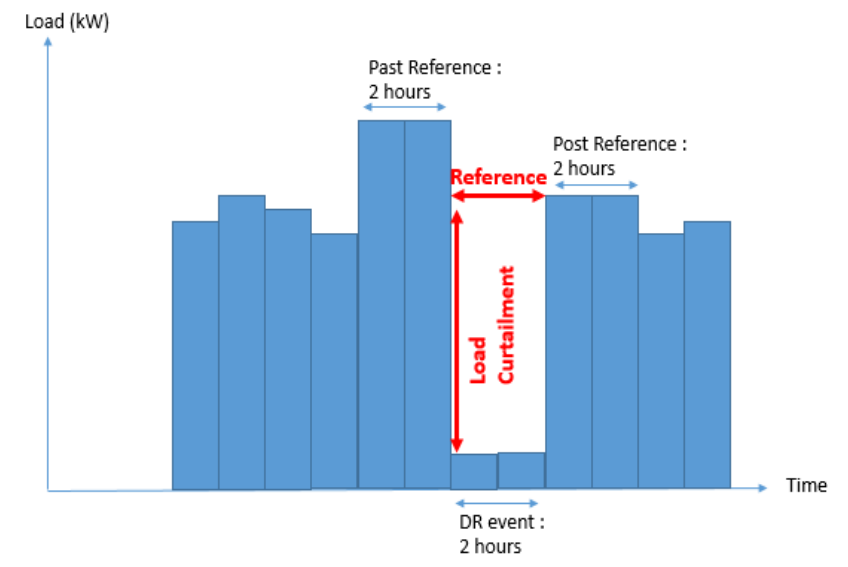

Fig. 2. Illustration of reference periods and Load curtailment.

\section{MATHEMATICAL MODEL}

Optimal pump scheduling problem in Drinking Water Systems is a long-standing problem in the literature [11]. It is a NP-Hard problem [12] aiming to find optimal schedules of pumps allowing to meet all water system constraints at minimum cost. Our study proposes to integrate another economic stake in the objective function, which is the revenues earned by trading DR on the spot market through the NEBEF mechanism.

The hypothesis made in this study is that the water utility acts on the spot market as a DR operator and seeks to maximize its own profits. Both the biddings of the water 
utility on the power exchange and the operation of pumps are scheduled in day ahead in order to maximize the overall profitability of the system while respecting various constraints of the water network. DR blocs are put on sale in winter and only during the evening peak (18:00 to 20:00) since it corresponds to annual national peak load, where the power system needs DR to replace the high-cost high-emissions peak generation units (coal, gas, diesel).

However, planning one day ahead (day D-1) the amount of electricity consumption to be reduced (in day D) during peak times represents a challege for water utilities due to the uncertainties about water demands over the network. It requires well-formulated operating schedules for pumps and risk-management to ensure that the water level in tanks remains in the operational range at minimum cost. In addition, a minimum of financial viability is required to water utilities in order to participate in DR schemes. A key factor to adress these challeges is the use of mathematical programming to produce optimal pump operation schedules with respect to all water network constraints while maximizing the utility of DR in markets.

The objective is to find, one day-ahead, optimal decisions on the functioning of equipment and the DR power reduction to sell on the market, allowing to respect all the constraints of the water system and covering risks linked to uncertainties of the water demand. For the modelling of uncertainties, we consider that we have an initial forecast of the water demand $d^{\text {forc }}$, but it is uncertain and then included in an interval $\left[d_{t}^{\min }, d_{t}^{\max }\right]_{t=1,2 \ldots T}$. Step-times are discretized into one hour interval periods. The following notations are then used:

- $x_{i, t}$ : The state of the pump $i$ at period $t(1,0)$

- $C_{i, t}$ : The electric cost when pump $i$ is $\mathrm{ON}$ at period $t$.

- $P_{i, t}$ : The power activated by pump $i$ at period $t$.

- $P^{D R}$ : The electric power (DR block) put on sale (bid) on the spot market for the period 18:00 - 20:00 (in $\mathrm{kW}$ ).

- $P_{\min }^{D R}:$ minimum DR bid allowed for NEBEF (in $\mathrm{kW}$ )

- $r$ : The market spot price for the period 18:00 - 20:00 (in $€ / \mathrm{kWh})$.

- $\rho$ : The compensation price for the period 18:00 - 20:00 (in $€ / \mathrm{kWh}$ ).

- $d_{t}$ : water demand at period $t$.

- $S_{t}:$ tank level at period $t$.

- $t^{D R}:$ the DR period, 18:00 to 20:00.

- $t^{\text {past }}:$ the past reference period, $16: 00$ to $18: 00$.

- $t^{\text {post }}:$ The post reference period, 20:00 to 22:00.
The objective function, which aims to minimize pumping costs while maximizing the economic value of load shedding at peak times, can be written as follows:

$$
\min _{x_{i, t}, P^{D R}} \sum_{i, t} C_{i, t} x_{i, t}-P^{D R}(r-\rho)
$$

The decision variables are the state of pumps and the power to put on sale for DR. The first term of the objective function is related to energy costs and the second term is linked to DR financial benefits.

In general, the constraints related to the management of a water system are either physical constraints (minimum and maximum operating levels of reservoirs), regulatory constraints (conditions of water resources withdrawal imposed by public authorities) and operational constraints (specific management modes related to each system). Since all these constraints are often encountered in literature, we will denote them by DWS classical constraints, to which the following equations are added:

$$
\begin{aligned}
& P^{D R} \geq P_{\min }^{D R} \\
& \sum_{i} P_{i, t_{1}} \cdot x_{i, t_{1}} \geq P^{D R}+\sum_{i} P_{i, t_{2}} \cdot x_{i, t_{2}} \\
& \forall t_{1} \in\left\{t^{\text {past }}, t^{\text {post }}\right\}, \forall t_{2} \in t^{D R} \\
& s^{\min }+d_{t}^{\max }-d_{t}^{\text {forc }} \leq s_{t+1} \leq s^{\max }+d_{t}^{\min }-d_{t}^{\text {forc }}
\end{aligned}
$$

Equation (1) represents the minimum power reduction in $\mathrm{kW}$ allowed to be traded for the NEBEF mechanism. Equation (2) models the past and post reference powers before and after the DR event. Finally, constraint (3) forces the level of the reservoir for the next time step, to be in the operationalmanagement field of the reservoir (between minimum and maximum volumes), corrected with the difference between forecasted and extreme demands.

The final problem of optimizing DR bids and the operation of pumps on day ahead can be written as a combination of the objective function, DWS classical constraints, and constraints (1), (2) and (3). The problem is formulated as a mixed integer linear programming (MILP) problem as follows:

\section{Problem 1:}

$$
\min _{x_{i, t}, P^{D R}} \sum_{i, t} C_{i, t} x_{i, t}-P^{D R}(r-\rho)
$$

Subject to:

- DWS Classical constraints

- Constraints (1)-(2)-(3)

\section{NUMERICAL RESULTS}

In this section, optimal water system management with DR participation is evaluated. Then, water system's strategies regarding bids on the spot market are analyzed, according to spot price scenarios. Finally, the benefits for using water system's flexibility for power system management are discussed. The optimization problem Problem 1 have been resolved for a range of market price scenarios using the 
Branch and Bound algorithm B\&B under the CPLEX optimization solver [13].

\section{A. Simulation Data}

A real drinking water system in France is used as benchmark. It contains one production plant, 11 pumping stations, and 14 distribution reservoirs. The average daily water demand of the system is about $50,000 \mathrm{~m}^{3}$ in winter.

A water demand history of 32 scenarios is available in winter for the system, which is used to build the forecasted, the maximum and the minimum hourly water demand profiles. The method of construction of extreme demands (max and min) is performed by taking an upper and lower envelope over a proportion $p$ of historic scenarios. The choice of the scenarios on which the envelopes are calculated is such that the area between maximum and minimum envelopes is minimal (the mathematical method allowing to extract these scenarios will not be detailed in this article).

As shown in Fig. 3, the hourly water demand profile is similar to that of the electricity load. The forecasted profile is built by taking an arithmetic mean on the 32 historical demands while extrem demands are built by taking upper and lower bound on a fixed number of 25 scenarios, corresponding to $80 \%$ of scenarios. The $80 \%$ value has been chosen because it corresponds to a safe level of control of uncertainties.

For numerical simulations, data for the year 2016 in winter are used, corresponding to spot and compensation prices between 18:00 and 20:00. Spot prices are available in the French power exchange (Epex Spot) website while compensation price was $56.10 € / \mathrm{MWh}$ in winter 2016 at peak times [9].

\section{B. Optimal Water System Management}

Resolution of problem 1 gives optimal schedules for pumps, an optimized management of tank levels covering potential water demand uncertainties, and optimal peak power reduction to be sold on the market via the DR NEBEF mechanism. For an average spot price of $81 € / \mathrm{MWh}$ for the year 2016, some simulation results are presented in Fig. 4 and Fig. 5.

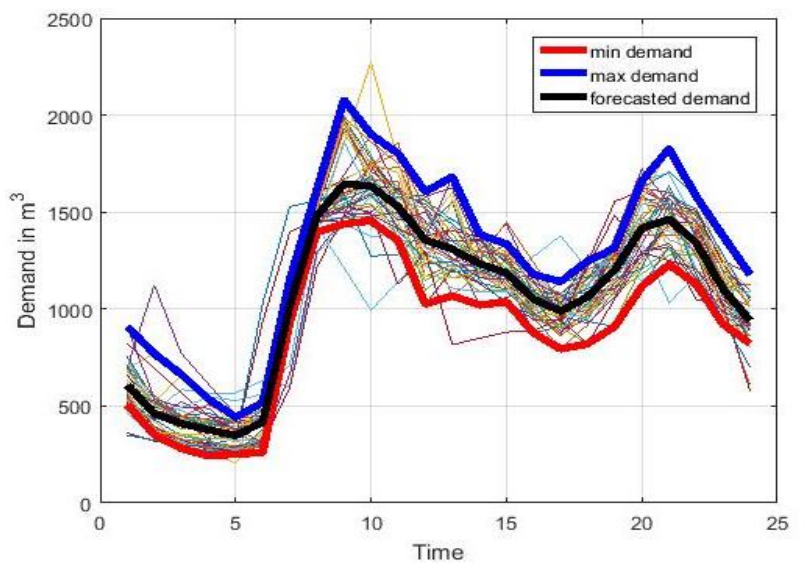

Fig. 3. Max, min and forecasted water demand profiles $(p=0.8)$.

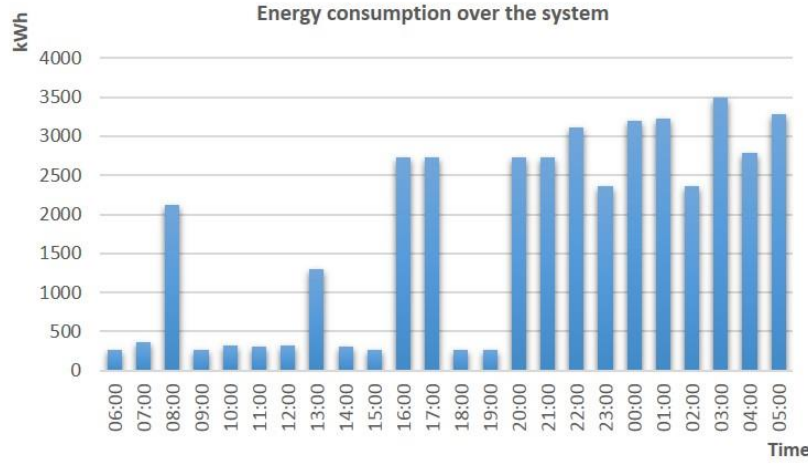

Fig. 4. Optimal energy consumption over the system.

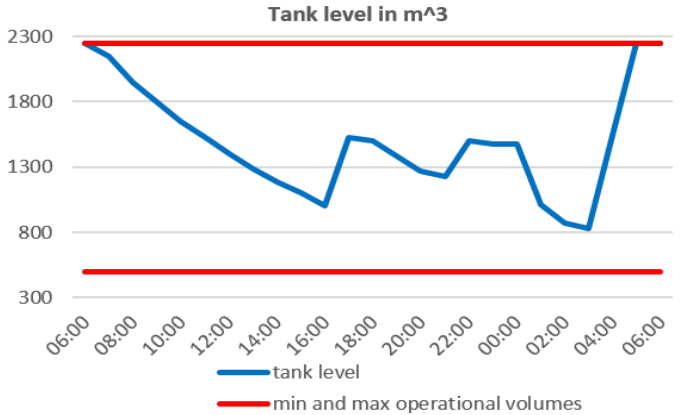

Fig. 5. Tank level evolution with DR consideration.

As shown in Fig. 4, pumping operations are minimized for the water system during peak hours (06:00 to 20:00) to meet demand at minimum cost. Meanwhile, tank levels gradually decrease, without reaching the minimum level of security in order to anticipate possible water demand forecasting errors (see Fig. 5). However, a higher activity of pumps is observed at off-peak hours (20:00 to 06:00) to take advantage of cheapest electricity tariffs. During the DR period, tanks level drop as pumping operations are minimized, but it does not reach the minimum level of security in anticipation of unexpected water demand hazards. On the other hand, some peak hours experience pumping operations:

- During the morning water peak period 08:00 when water demand is very high;

- Midday at 13:00 to anticipate possible water demand hazards;

- The past reference period, $16: 00$ to $18: 00$ to have a water reserve during the DR event (18:00 to 20:00)

\section{DR Bids Strategies and Impact on the Power System}

Problem 1 has been resolved for a range of spot prices. The reported results are optimal DR powers allowing to maximize the profitability of the water system while respecting all constraints. The net benefit is defined as the difference between spot price and compensation. Simulation results as well as net benefit ranges for winter 2016 between 18:00 and 20:00 are presented in Table I. 
Table I. Net benefit ranges frequency between 18:00 and 20:00

\begin{tabular}{|c|c|c|c|c|}
\hline $\begin{array}{c}\text { Net benefit } \\
(€ / M W h)\end{array}$ & $<0$ & $1-50$ & $51-100$ & $>100$ \\
\hline Frequency (\%) & $4.5 \%$ & $74 \%$ & $6.5 \%$ & $15 \%$ \\
\hline DR power ( MW) & 0 & $2-2.4$ & $2.4-2.5$ & $2.5-2.74$ \\
\hline
\end{tabular}

As shown in Table I, the NEBEF mechanism was not financially viable in $4.5 \%$ of the time since spot prices were less than compensation price (negative net benefit). This implicitly implies that the power system did not need any DR because the available generation was sufficient to meet the requested demand at minimum cost.

For the positive net benefit ranges, the function of evolution of optimal DR power reduction is obviously growing with market price (see Fig. 6). This is justified by the objective function which aims to maximize the economic value of DR. The function is concave and the slope is decreasing with the price. The optimal DR power is:

- Very sensitive for prices between 0 and $100 € / \mathrm{MWh}$ since the water system still has enough flexibility to react to the price signal;

- Minimally sensitive for prices between 100 and 400 $€ / \mathrm{MWh}$ since the water system has only reduced available flexibility;

- Constant for prices $>400 € / M W h$ since the water system used its maximum DR power capacity.

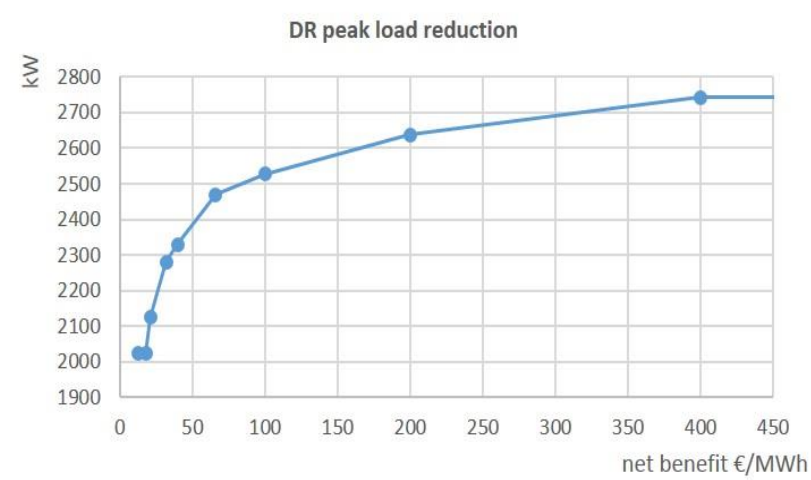

Fig. 6. DR peak load reduction according to market price

On the other hand, the DR peak load reduction curve is compatible with the needs of the electric power system. The high price periods correspond to the most stressed supply/demand equilibrium periods on the market, when highcost high-emissions fossil generation units are the most solicited and when DR is the most useful.

This power reduction will be then sold on the market as a "virtual production" and will replace an equivalent fossil electricity production according to the market's merit order principle. In fact, bids are accepted in the market according to their operating cost. We find renewables on the bottom of the supply curve, followed by nuclear production since they have low operating cost. After, we find peak generation units, starting with coal-fired power plants, then combined cycle gas plants (CCGT) and ending with diesel fueled since they have the highest running cost (see Fig. 7).

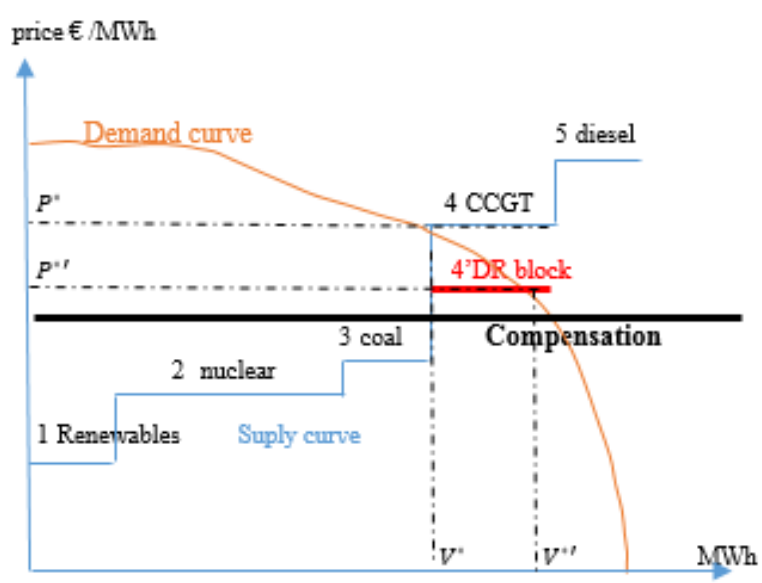

Fig. 7: Merit order principle and DR impact on the supply curve

As shown in Fig. 7, the DR bloc 4'would be inserted between other peak generation unit's blocs, depending on the DR bid's price and peak generations unit's variable cost. If the DR bid's price is competitive (large volume), it could also lower market price.

\section{Discussion}

The development of Demand Side management in the industrial sector could be hampered by two obstacles, those being financial viability and risk management [14]. Industrials could be reluctant to participate in DR programs if they do not well manage uncertainties and risks about their systems functioning. At the same time, they must ensure a sufficient financial viability for DR participation to remain competitive in markets. Mathematical programming could address both of these challenges, as shown in this article for the water industry where the case of a medium size water system was discussed. The mathematical model used allows to:

- Estimate, on the basis of a water demand history, the extreme water demands with a certain degree of robustness $p \in[0,1]$;

- Secure the operation of the system regarding water demand hazards by keeping an extra water volume margin in tanks (optimization of tank level management);

- Optimize DR load reduction powers by scheduling pumps.

The study can be extended to aggregate the flexibility of several water systems in order to propose large volumes of peak load reduction enabling to improve power system's reliability at peak times. The expected benefits of this aggregation would be:

- Increasing competition in energy markets by encouraging DR participation;

- Reducing the use of fossil generation units and $\mathrm{CO}_{2}$ emissions to deal with peak load periods;

- Generating economic gains on water utilities electricity bill by optimizing power reduction to be sold for DR. 


\section{CONCLUSION}

The presence of storage units such as tanks and reservoirs gives Drinking Water Systems a flexibility they can use to facilitate the transition to a sustainable energy system by adapting electricity consumption to power system's needs. The use of mathematical programming can enable water system operators to participate in DR mechanisms such as NEBEF mechanism, allowing to reduce peak energy load and $\mathrm{CO} 2$ emissions while generating economic gains on water utilities electricity bills. Moreover, taking into account uncertainties about water demands in the mathematical model secures the operation of water systems in real time regarding hazards about water demands. Combination of these elements (mathematical programming + uncertainties) then could give water utilities more confidence to participate in efficient Demand Response programs.

\section{REFERENCES}

[1] World Energy Council, "World Energy Resources 2016", 2016.

[2] R. Boisvert, P. Cappers et B. Neenan, "The benefit of customer participation in wholesale electricity markets," Electricity Journal, vol. $15, \mathrm{n}^{\circ} \% 13$, pp. 41-51, 2002.
[3] A. Gholian, H. Mohsenian-Rad et Y. Hua, "Optimal industrial load control in smart grid: A case study for oil refineries," chez IEEE PES General Meeting, Vancouver, Canada, July 2013.

[4] S. Bunn, "Closing the loop in water supply optimization," water Event, IET, pp. 71-82, 2007

[5] S. Bunn, "Reducing the GHG footprint at water and wastewater utilities in the US and the UK," Derceto, 2011.

[6] S. Pierluigi, "Demand Response and Smart Grids - A Survey," Renewable and Sustainable Energy Reviews, vol. 30, pp. 461-478, 2014.

[7] R. Menke, E. Abraham, P. Parpas et I. Stoianov, "Demonstrating demand response from water distribution system through pump scheduling," Journal of Applied Energy, vol. 170, pp. 377-387, 2016.

[8] T. Veyrenc, "Market design for Demand Response : the French experience," International Energy Agency, 2014

[9] RTE, "Règles pour la valorisation des effacements de consommation sur les marchés de l'énergie, " 2016.

[10] RTE, «Bilan Sûreté 2010,» 2011

[11] G. Bonvin, S. C. Le pape et N. Maïzi, "A convex Mathematical Program for Pump Scheduling in a Class of Branched Water Networks," chez 7th International Conference on Applied Energy (ICAE2015), Abu Dhabi, UAE, 2015

[12] L.-B. De la perrière, A. Jouglet et D. Nace, "Optimisation de la gestion des réseaux d'eau potable par la programmation linéaire en nombre entiers," PhD Thesis, Université de Technologie de Compiègne, 2011.

[13] https://www-01.ibm.com/software/commerce/optimization/cplexoptimizer/

[14] V. Rious, Y. Perez et F. Roques, "Which electricity market design to encourage the development of demand response ?" Economic Analysis and Policy, vol. 48, pp. 128-138, 2015. 